\title{
Interactions between Apolipoprotein E Gene and Dietary $\alpha$-Tocopherol Influence Cerebral Oxidative Damage in Aged Mice
}

\author{
Erin E. Reich, ${ }^{1}$ Kathleen S. Montine, ${ }^{1}$ Myron D. Gross, ${ }^{2}$ L. Jackson Roberts II, ${ }^{1}$ Larry L. Swift, ${ }^{1}$ \\ Jason D. Morrow, ${ }^{1}$ and Thomas J. Montine ${ }^{1}$ \\ ${ }^{1}$ Departments of Pathology, Medicine, and Pharmacology and Center for Molecular Neurosciences, Vanderbilt University \\ Medical Center, Nashville, Tennessee 37232, and 2Department of Pathology and Laboratory Medicine, University of \\ Minnesota, Minneapolis, Minnesota 55455
}

Cerebral oxidative damage is a feature of aging and is increased in a number of neurodegenerative diseases. We pursued the gene-environment interaction of lack of apolipoprotein $\mathrm{E}(\mathrm{apoE})$ and modulation of dietary $\alpha$-tocopherol on cerebral oxidative damage in aged male and female mice by quantifying the major isomers of cerebral isoprostanes, derived from arachidonic acid (AA) oxidation, and neuroprostanes, derived from docosahexaenoic acid (DHA) oxidation. Mice fed $\alpha$-tocopherol-deficient, normal, or -supplemented diet had undetectable, $4486 \pm 215$, or $6406 \pm 254 \mathrm{ng}$ of $\alpha$-tocopherol per gram of brain tissue $(p<0.0001)$, respectively. Two factors, male gender and lack of apoE, combined to increase cerebral
AA oxidation by $28 \%$, whereas three factors, male gender, lack of apoE, and deficiency in $\alpha$-tocopherol, combined to increase cerebral DHA oxidation by $81 \%$. $\alpha$-Tocopherol supplementation decreased cerebral isoprostanes but not neuroprostanes and enhanced $\mathrm{DHA}$, but not $\mathrm{AA}$, endoperoxide reduction in vivo and in vitro. These results demonstrated that the interaction of gender, inherited susceptibilities, and dietary $\alpha$-tocopherol contributed differently to oxidative damage to cerebral AA and DHA in aged mice.

Key words: aging; mouse; brain; apolipoprotein E; $\alpha$-tocopherol; oxidative damage; isoprostanes; neuroprostanes
Aging is a complex trait that derives critical input from genetic and environmental factors. A substantial body of data support a pivotal role for oxidative stress as a key effector in both genetic and environmental aspects of aging (Finkel and Holbrook, 2000). Increased oxidative stress contributes to aging through mechanisms that involve structural damage to cellular macromolecules (Halliwell, 1992). These irreversible modifications can have several deleterious effects on cell function, including oxidative modification of nucleic acids, that are thought to contribute to altered gene expression in aging (Beckmam and Ames, 1998).

Recently, others quantified age-related change in expression of over 11,000 genes in mouse cerebral cortex and hypothalamus; apolipoprotein $\mathrm{E}$ ( $a p o E$ ) was among the few genes that showed significantly reduced expression in both regions of brain (Jiang et al., 2001). Importantly, lack of apoE is associated with increased oxidative damage in aged mouse brain (Montine et al., 1999a; Pratico et al., 1999). Moreover, inheritance of the $\epsilon 4$ allele of human apolipoprotein E gene (APOE4) is associated with poorer cognitive performance with age and an increased risk of developing Alzheimer's disease (AD) (Mahley and Huang, 1999). The isoform encoded by $A P O E 4$, apoE4, may be deficient in some critical function(s) relative to the other common isoforms of apoE (Mahley and Huang, 1999) or may have dominant negative

Received April 26, 2001; revised June 1, 2001; accepted June 6, 2001.

This work was supported by National Institutes of Health Grants AG00774, AG16835, and AG05114, as well as a grant from the Alzheimer's Association (T.J.M.) and a Burroughs-Welcome Clinical Scientist Award in Translational Research (J.D.M.). We thank Bill Zackert, Ling Gao, Stephanie Sanchez, and Erin Terry for their expert assistance.

Correspondence should be addressed to Dr. Thomas J. Montine, Department of Pathology, Vanderbilt University Medical Center, C-3321A Medical Center North, Nashville, TN 37232. E-mail: tom.montine@mcmail.vanderbilt.edu.

Copyright (ㄷ) 2001 Society for Neuroscience $0270-6474 / 01 / 215993-07 \$ 15.00 / 0$ effects (Buttini et al., 2000). Some groups have associated homozygosity for $A P O E 4$ with increased markers of brain oxidative damage (Montine et al., 1998; Pratico et al., 2000); however, this association has not been consistent among laboratories or methods used to detect oxidative damage (Sayre et al., 1997; Montine et al., 1999c). Together, these data suggest that reduced apoE activity, from either decreased expression with advancing age or inheritance of $A P O E 4$, may contribute to oxidative damage to brain.

Vitamin E is a family of tocopherols, of which $\alpha$-tocopherol is the most biologically active antioxidant in vivo (Marcus and Coulston, 1996). At physiologic concentrations, $\alpha$-tocopherol acts as a lipophilic radical scavenger and thereby limits lipid peroxidation, although it may have other actions (Thomas and Stocker, 2000). Dietary supplementation with $\alpha$-tocopherol appears to impede the progression of some age-related diseases that are associated with increased oxidative damage, including atherosclerosis (for review, see Jialal et al., 2001) and possibly AD (Sano et al., 1997); however, the effects of $\alpha$-tocopherol dietary supplementation in patients with established AD were modest. These results raise the possibilities that $\alpha$-tocopherol may not be an effective antioxidant in brain or that $\alpha$-tocopherol may have activity other than radical scavenging in those regions of brain affected by AD.

We showed previously that free radical damage to arachidonic acid (AA) and docosahexaenoic acid (DHA) in brain can be quantified by measuring isoprostanes (IsoPs) and neuroprostanes (NPs), respectively, highly accurate and specific markers of free radical-mediated damage (Roberts et al., 1998; Roberts, 2000). Additionally, because the major isomers of IsoPs and NPs, F-ring or D/E-ring compounds, derive from common endoperoxide intermediates by reduction or isomerization, respectively, the ratio 
of F- to D/E-ring compounds is a measure of the reducing environment in which oxidation occurred (Reich et al., 2000, 2001). Here we used these quantitative endpoints to test the hypothesis that there is a gene-environment interaction between apoE and $\alpha$-tocopherol with respect to age-related oxidative damage to mouse cerebrum.

\section{MATERIALS AND METHODS}

Mice and tissue acquisition. The primary study group consisted of 63 mice purchased from The Jackson Laboratory (Bar Harbor, ME) at 3 weeks of age. Mice were either C57BL/6J [wild type (wt)] or apoE $-/-$ mice (C57BL/6J-Apoetm1Unc) backcrossed six to eight generations with C57BL/6L mice and were weighed every $4-8$ weeks. These mice were divided among three different diets (vida infra). A second study group of eight wt and eight apoE $-/-$ mice was purchased from the same vendor at the same age and housed under the same conditions as the primary study group; these mice were fed standard mouse food. Three mice, two wt and one apoE $-/-$, died within a month of purchase. The remaining 60 mice were aged 9 months on the different diets and were killed at 39 weeks of age. While under deep anesthesia, $0.5-1 \mathrm{ml}$ of blood was collected. Brains were removed immediately and sectioned into two cerebral hemispheres and cerebellum. Tissue and plasma were flash frozen in liquid nitrogen and were kept frozen at $-80^{\circ} \mathrm{C}$ until analyzed.

Diets. All diets for the primary study group were purchased from Harlan Teklad (Madison, WI). Mice were reared on one of three different diets from the age of 3 weeks: a normal diet containing $50 \mathrm{IU}$ of $\alpha$-tocopherol per kilogram of food, a deficient diet containing 0 IU of $\alpha$-tocopherol per kilogram of food, and a supplemented diet containing 500 IU of $\alpha$-tocopherol per kilogram of food. The $\alpha$-tocopherol-deficient diet was formulated from tocopherol-stripped corn oil as the base material, with remaining dietary requirements, excluding $\alpha$-tocopherol, added to this base. For the normal and supplemented diets, all-rac- $\alpha$-tocopherol acetate was added to the $\alpha$-tocopherol-deficient diet at levels of 50 and $500 \mathrm{IU}$ per kilogram of food, respectively. Fresh food was received every 3 weeks and was changed in all cages biweekly to prevent oxidation. All mice received food and water ad libitum.

Quantitative methods. F-Ring and D/E-ring IsoPs, NPs, and fatty acids were measured in one cerebral hemisphere as described previously (Reich et al., 2001). Briefly, each cerebrum was weighed and homogenized in Folch solution. Subsequently, lipids were extracted by the method of Folch. $\mathrm{D}_{2} / \mathrm{E}_{2}$-IsoPs and $\mathrm{D}_{4} / \mathrm{E}_{4}-\mathrm{NPs}$ esterified in tissue were converted to $O$-methyloxime derivatives in Folch solution, and all compounds were hydrolyzed by chemical saponification. F-Ring and D/Ering IsoPs and NPs were analyzed using gas chromatography (GC) with negative ion chemical ionization mass spectrometry and selective ion monitoring as described previously (Reich et al., 2001). Data are presented for the separate compounds, total IsoPs or NPs (sum of F-ring and $\mathrm{D} / \mathrm{E}$-ring compounds), or the ratio of F-ring to D/E-ring compounds. Cerebral AA and DHA concentrations were determined as described previously (Montine et al., 1999a). Briefly, an aliquot of Folch extract from each tissue sample was transmethylated, and the total fatty acid composition was quantified using GC with flame ionization detection. $\alpha$-Tocopherol was quantitated in plasma and cerebellum using a published HPLC-electrochemical detection method (Gross et al., 1995).

Synaptosomes. Rat cerebral synaptosomes were prepared and oxidized with AAPH as described previously (Reich et al., 2000). Briefly, synaptosomes were preincubated with varying concentrations of $\alpha$-tocopherol for $1 \mathrm{hr}$ and then oxidized by incubation with 2,2'-azobis(2amidinopropane)dihydrochloride (AAPH) at $37^{\circ} \mathrm{C}$ for $2 \mathrm{hr}$. Reactions were terminated by placing samples at $-80^{\circ} \mathrm{C}$. Quantification of F-ring and D/E-ring IsoPs and NPs were performed as described above for mouse cerebrum.

Statistical analysis. Statistical analyses were performed using Graph Pad Prism 3.0 software (San Diego, CA)

\section{RESULTS}

For the primary study group, we obtained 63 mice immediately after weaning ( 3 weeks of age) and maintained them on a diet of mouse food with normal levels of $\alpha$-tocopherol (50 IU/kg), food supplemented with $\alpha$-tocopherol (500 IU/ kg), or food lacking $\alpha$-tocopherol for the rest of their lives. As expected, male mice weighed more than female mice at all time points (Fig. 1). All

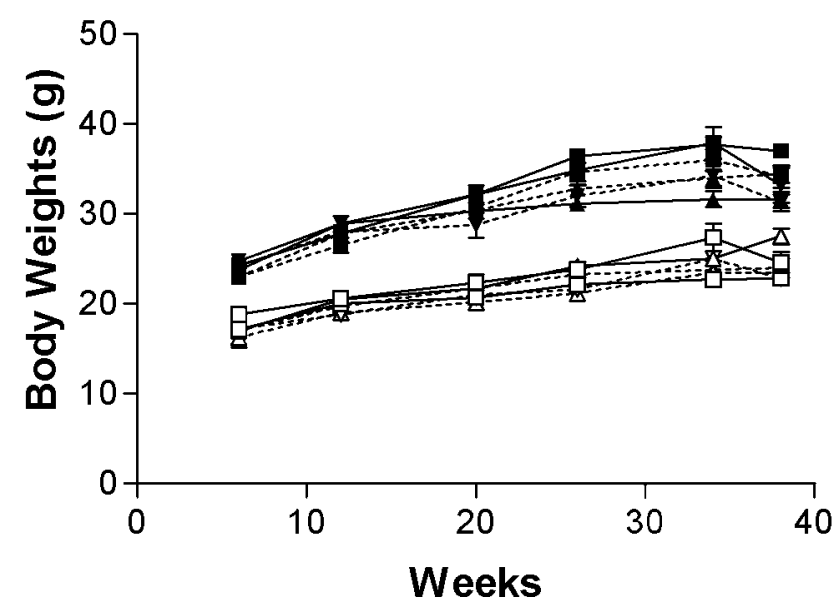

Figure 1. Body weights of the 60 mice in the primary study group versus age. Male and female mice are represented with filled and open symbols, respectively. Genotypes are either wt (solid lines) or apoE $-/-$ (dashed lines). Diets are either $\alpha$-tocopherol-deficient (inverted triangles), normal (squares), or supplemented (triangles). Data are mean \pm SEM weights for all mice in each group. Male mice weighed significantly more than female mice at all ages. Two-way ANOVAs for genotype versus diet for weight at 39 weeks of age had $p<0.05$ for genotype in males and $p<0.05$ for genotype in females. Diet was not significantly related to body weight in males or female.

groups of mice gained weight over the first 6 months and then either gained weight or maintained weight from 6-8 months of age. From 8-9 months, some groups of wt and apoE $-/-$ mice showed a slight reduction in body weight, although it was not statistically significant. Therefore, we terminated the study at 39 weeks of age, after 9 months on the different diets. Body weights in males or females were analyzed by two-way ANOVA at 39 weeks of age. In both male and female mice, apoE genotype was weakly related to lower body weight $(p<0.05$ for both males and females). Diet was not related to body weight in male or female mice.

Previously, we reported that cerebral $\mathrm{F}_{2}$-IsoPs are modestly elevated in aged apoE $-/-$ mice, a finding confirmed by others (Montine et al., 1999a; Pratico et al., 1999). apoE -/- mice in the present study reared on the normal diet had total IsoP levels of $16.8 \pm 1.2 \mathrm{ng} / \mathrm{gm}$, whereas wt mice on the normal diet had levels of $13.5 \pm 0.5 \mathrm{ng} / \mathrm{gm}\left(t_{24}=2.41 ; p<0.05\right)$. Total IsoP levels were stratified into four groups according to both gender and genotype and compared by ANOVA $\left(F_{(3,24)}=4.14 ; p<0.05\right)$. Interestingly, corrected repeated-pairs comparisons showed that total IsoP levels were significantly elevated in apoE $-/-$ male mice compared with wt males $(p<0.05)$ but not apoE $-/-$ female mice compared with wt females. This novel observation of a gender-specific effect of lack of apoE on cerebral oxidative damage was also present in a separate set of eight wt and eight apoE -/mice (equally divided between genders) aged to 9 months under the same conditions and fed standard mouse food (data not shown). The combined results from these two experiments are presented in Figure 2. One-way ANOVA for the combined data set was highly significant $\left(F_{(3,40)}=5.88 ; p<0.002\right)$, and corrected repeated-pairs comparisons showed significantly elevated cerebral total IsoP levels in apoE $-/-$ male mice compared with wt male mice $(p<0.01)$ and apoE $-/-$ female mice $(p<0.01)$; wt females did not differ from apoE $-/-$ females. In contrast to total IsoPs, ANOVA for total NPs was not statistically significant for the 


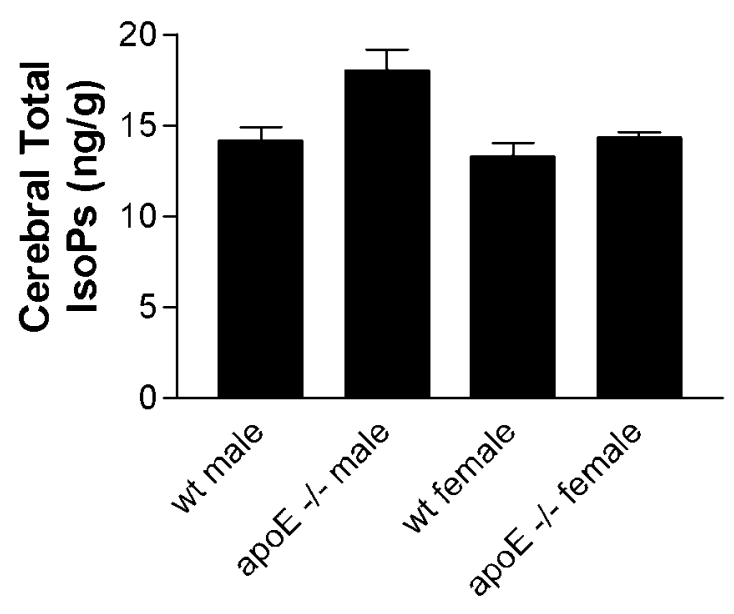

Figure 2. Cerebral total (sum of F-ring and D/E-ring) IsoPs in mice from both the primary study group maintained on diet with normal $\alpha$-tocopherol levels and the secondary group raised on normal mouse food stratified by genotype and gender. Data are mean \pm SEM for each group. One-way ANOVA $\left(F_{(3,40)}=5.88\right)$ had $p<0.002$ with corrected repeatedpairs comparisons showing significant differences between wt male versus apoE $-/-$ male mice $(p<0.01)$ and apoE $-/-$ male versus apoE $-/-$ female mice $(p<0.01)$.

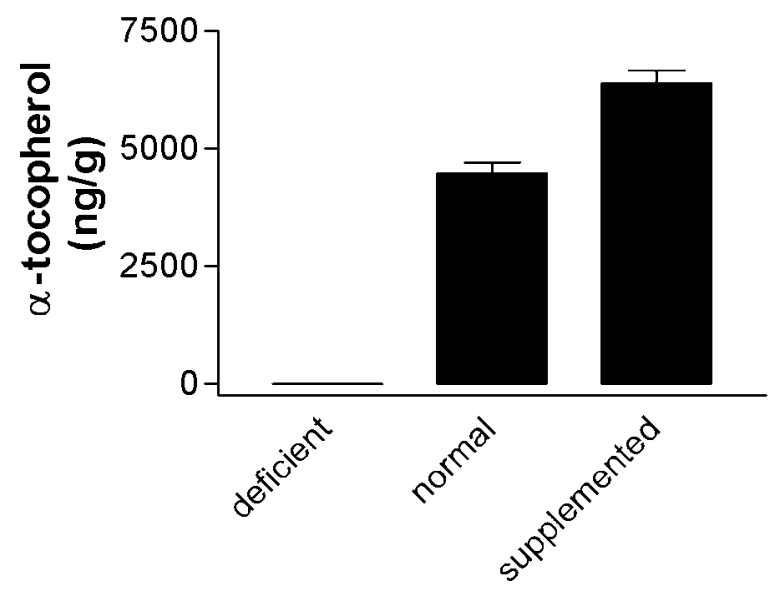

Figure 3. Brain $\alpha$-tocopherol levels were quantified in cerebellum from each mouse using HPLC with electrochemical detection, and the mean \pm SEM values for mice on the three different diets are presented (one-way ANOVA had $p<0.0001)$. Mice were reared on one of three different diets from 3 to 39 weeks of age. Diets were prepared from tocopherol-stripped base material with no (deficient), $50 \mathrm{IU} / \mathrm{kg}$ (normal), or $500 \mathrm{IU} / \mathrm{kg}$ (supplemented) all-rac- $\alpha$-tocopherol acetate added.

primary group alone $\left(F_{(3,24}=1.8 ; p=0.19\right)$ or when combined with the second group of mice $\left(F_{(3,40)}=1.5 ; p=0.22\right)$.

We determined the concentrations of $\alpha$-tocopherol in plasma and cerebellum to assess the efficacy of the different diets to modulate endogenous $\alpha$-tocopherol levels. Plasma $\alpha$-tocopherol levels were $0.01 \pm 0.00,0.50 \pm 0.10$, or $1.47 \pm 0.26 \mathrm{mg} / \mathrm{dl}$ for mice on the deficient, normal, or supplemented diet, respectively $\left(F_{(2,54)}=7.93 ; p<0.0001\right.$; corrected repeated-pairs comparisons had $p<0.05$ for normal vs deficient diets and $p<0.01$ for normal vs supplemented diets). Brain $\alpha$-tocopherol levels also varied significantly with diet $\left(F_{(2,55)}=280 ; p<0.0001\right)$ (Fig. 3); repeated-pairs comparisons showed that brain $\alpha$-tocopherol levels were significantly greater in mice reared on the supplemented diet $(p<0.001)$ and significantly less in mice reared on the deficient diet $(p<0.001)$ compared with mice reared on the
A

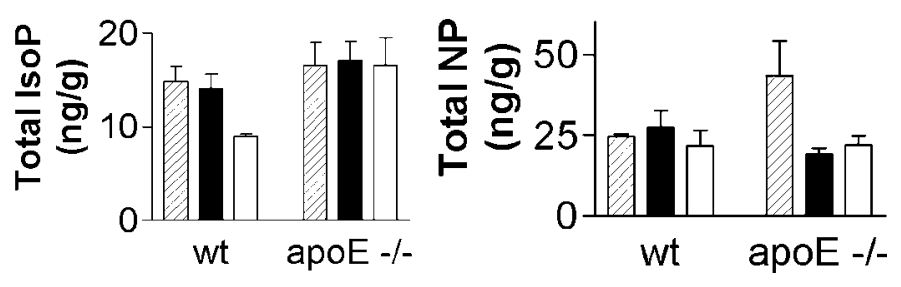

Figure 4. A, Cerebral total (sum of F-ring and D/E ring) IsoPs in male mice were stratified according to genotype and diet, and the mean \pm SEM values are presented for each group. Two-way ANOVA was significant for genotype $(p<0.05)$ but not diet; there was no significant interaction between genotype and diet. Post hoc one-way ANOVAs showed that cerebral total IsoPs were significantly different among male wt $\left(F_{(2,17)}=\right.$ $7.89 ; p<0.005$ ), but not $a p o E-/-$, mice. $B$, Cerebral total (sum of F-ring and $\mathrm{D} / \mathrm{E}$ ring) NPs in male mice were stratified according to genotype and diet, and the mean \pm SEM values are presented for each group. Two-way ANOVA was significant for diet $(p<0.05)$ but not genotype alone; however, there was a significant interaction between genotype and diet $(p<0.05)$. Post hoc one-way ANOVAs showed that cerebral total NPs were significantly different among male apoE $-/-\left(F_{(2,17)}=6.61 ; p<\right.$ 0.01 ), but not wt, mice.

normal diet. There was a significant correlation between plasma and brain $\alpha$-tocopherol concentrations in all mice $(p<0.0001$; $\left.R^{2}=0.24\right)$. One-way ANOVAs for brain or plasma $\alpha$-tocopherol levels were not significant when data were stratified by gender and genotype into four groups.

We analyzed the effects of the different diets on total IsoPs or NPs by two-way ANOVA for wt versus apoE - /- mice of each gender. In male mice, two-way ANOVA for total IsoP was significant for genotype only $(p<0.05)$ but not for diet or interaction between diet and genotype (Fig. 4A). Post hoc analysis with one-way ANOVA revealed that total IsoPs were significantly related to diet but only in wt male mice $\left(F_{(2,17)}=7.89 ; p<0.005\right)$. Corrected repeated-pairs comparisons showed that wt male mice on the supplemented diet had on average $37 \%$ lower total IsoPs compared with wt male mice on normal diet $(p<0.05)$; there was no difference in total IsoPs between normal and deficient diets. Two-way ANOVA for total IsoPs in female mice was not significant for genotype or diet (data not shown).

In contrast to total IsoPs in which genotype most strongly influenced variance in data in male mice, two-way ANOVA showed that total NPs in male mice were significantly influenced by diet $(p<0.05)$ but not genotype (Fig. $4 B$ ). Importantly, there was significant interaction between diet and genotype $(p<0.05)$. Post hoc one-way ANOVA showed that the combination of lack of apoE plus $\alpha$-tocopherol deficiency led to a near doubling of NPs in apoE $-/-$ male mice $\left(F_{(2,17)}=6.61 ; p<0.01\right)$; corrected repeated-pairs comparisons were significant for normal versus deficient diets ( $p<0.05$ for both genotypes) but not normal versus supplemented diets. Post hoc one-way ANOVA for total NPs in wt males on the different diets was not significant (Fig. $4 B$ ). Two-way ANOVA for cerebral total NP levels in female mice was not significantly related to diet or genotype (data not shown).

The ratio of F- to D/E-ring IsoPs and NPs can be used as a measure of reducing capacity of the environment in which oxidation of AA and DHA, respectively, occurred. Two-way ANOVAs for the F- to D/E-IsoP ratio was not significant for diet or genotype in male or female mice (data not shown). In contrast, two-way ANOVA for the F- to D/E-NP ratio in male mice was 


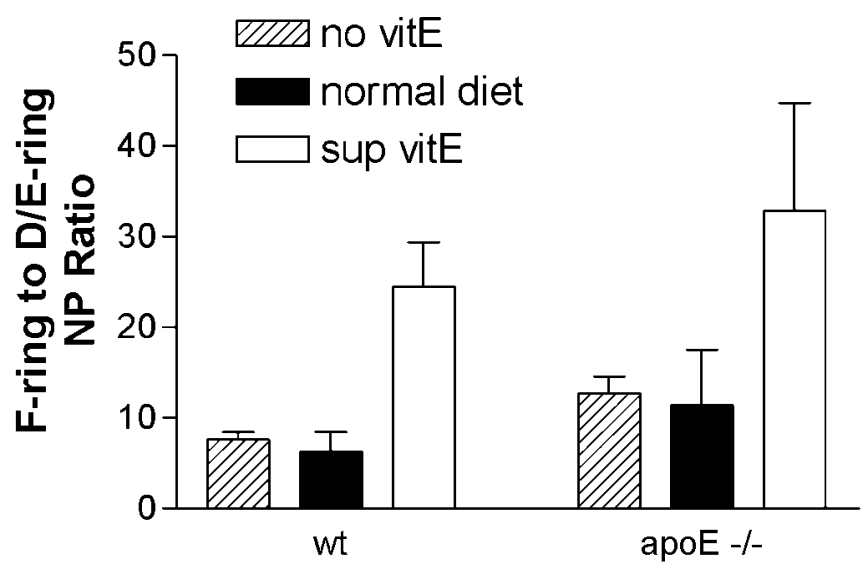

Figure 5. The ratios of cerebral F-ring to D/E-ring NPs in male mice were stratified according to genotype and diet, and the mean \pm SEM values presented for each group. Two-way ANOVA was significant for diet $(p<0.05)$ but not genotype or interaction between diet and genotype. Post hoc one-way ANOVAs with corrected repeated-pairs comparisons showed significantly increased ratios in mice of both genotypes on the $\alpha$-tocopherol-supplemented diet (sup vitE) compared with normal diet. There was no significant difference in the F-ring to D/E-ring ratio between mice on a normal diet and a $\alpha$-tocopherol-deficient diet (no vitE).

significant for diet $(p<0.01)$ but not genotype or interaction between diet and genotype. Post hoc one-way ANOVA for the effects of diet on the NP ratio in wt male mice was significant $\left(F_{(2,18)}=17.59 ; p<0.0001\right)$ (Fig. 5). Corrected repeated-pairs comparisons showed that the F- to D/E-NP ratio was significantly increased in wt male mice on the $\alpha$-tocopherol-supplemented versus normal diet $(p<0.01)$ but that there was no significant difference in NP ratio between deficient and normal diet. The relationship of F- to D/E-NP ratio to diet was remarkably similar in apoE -/- male mice compared with wt male mice (Fig. 5). One-way ANOVA for the effects of diet on NP ratio in male apoE $-/-$ mice was $F_{(2,18)}=3.65$ and $p<0.05$, with $p<0.05$ for normal versus supplemented diets. Two-way ANOVA for the Fto $\mathrm{D} / \mathrm{E}-\mathrm{NP}$ ratio in female mice was not significant for diet or genotype (data not shown).

We next determined the concentrations of cerebral AA and DHA in each mouse. Two-way ANOVA showed that cerebral DHA levels were significantly related to diet in male $(p<0.0001)$ and female $(p<0.0001)$ mice but not related to the presence or absence of apoE, nor was there an interaction between diet and genotype. Two-way ANOVA showed that cerebral AA levels were not significantly related to either diet or genotype. Post hoc one-way ANOVA showed that cerebral DHA levels were significantly increased in male and female mice on $\alpha$-tocopheroldeficient diets ( $p<0.05$ for both genders) and tended to be lower for mice of both genders on the supplemented diet compared with mice on the normal diet. Because of this association with diet alone in both genders, cerebral DHA levels were further analyzed by regression analysis with brain $\alpha$-tocopherol level; results for AA are included for comparison (Fig. 6). Cerebral DHA, but not AA, levels were significantly inversely related to brain $\alpha$-tocopherol concentrations $\left(R^{2}=0.51 ; p<0.0001\right)$. This unexpected association between deficiency of $\alpha$-tocopherol and increased cerebral DHA raised the possibility that the increased total NP levels observed in male apoE -/- mice may be attributable to increased substrate and not increased oxidative stress. Therefore, IsoP and NP levels were calculated per microgram of DHA or AA in the same sample, respectively, rather than per

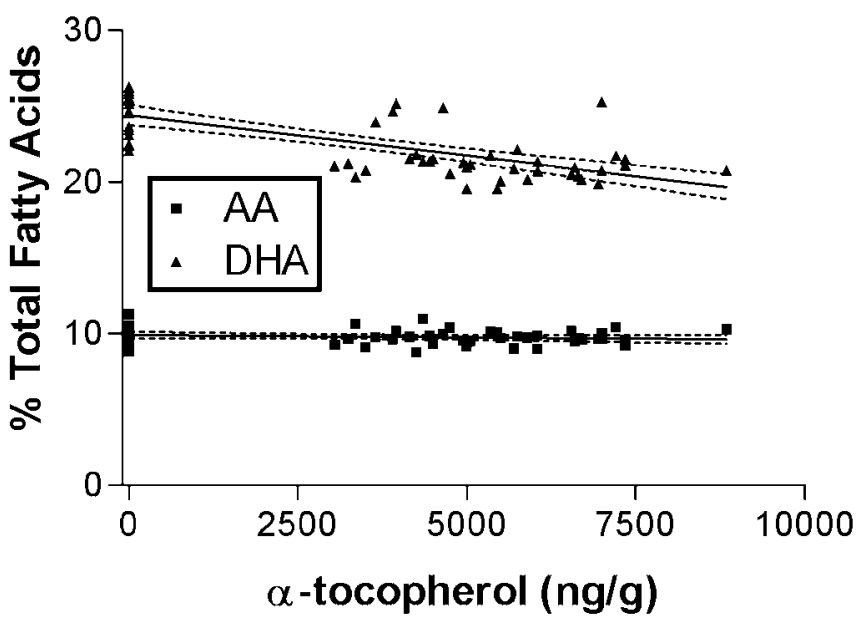

Figure 6. Cerebral AA and DHA concentrations as a percentage of total fatty acids were determined by GC and plotted versus brain $\alpha$-tocopherol concentrations. Linear regression analysis was performed, and the best-fit lines plus $95 \%$ confidence intervals also are plotted. There was a highly significant negative linear correlation between the percentage of cerebral fatty acids as DHA and the concentration of $\alpha$-tocopherol in brain $\left(R^{2}=\right.$ $0.51 ; p<0.0001)$. There was no significant relationship between cerebral AA levels and $\alpha$-tocopherol concentrations.

milligram of protein. When the data were reanalyzed, there was no change in the statistically significant relationships reported above. A summary of the statistically significant changes in mice on the deficient and supplemented diets relative to mice of the same gender and genotype on a normal diet is presented in Table 1.

We further investigated the ability of $\alpha$-tocopherol supplementation to promote reduction of the endoperoxide of DHA but not AA in rat brain synaptosomes oxidized ex vivo with AAPH. Previously, we showed that oxidation of rat brain synaptosomes under these conditions leads to time- and concentrationdependent increases in F-ring and D/E-ring IsoPs and NPs (Reich et al., 2000). Plasma levels of $\alpha$-tocopherol vary among individuals, but normal values are $\sim 10-50 \mu \mathrm{M}$ (Elin, 1996). Therefore, rat brain synaptosomes were exposed to a constant oxidative stress with $5 \mathrm{~mm}$ AAPH plus 0 , 1, 10, or $100 \mu \mathrm{M}$ $\alpha$-tocopherol for $24 \mathrm{hr}$ and then assayed for F- and D/E-ring IsoPs and NPs to model our in vivo experiments with $\alpha$-tocopheroldeficient, normal, and -supplemented diets. Similar to what has been observed with plasma low-density lipoprotein oxidized under similar conditions, $\alpha$-tocopherol displayed concentrationdependent pro-oxidant activity in this in vitro system, but only with DHA and not AA (Fig. 7A). One-way ANOVA showed that $\alpha$-tocopherol significantly increased total NP formation $\left(F_{(3,8)}=\right.$ 57.4; $p<0.0001)$ in the presence of AAPH and that this was significantly different from AAPH alone for only $10(p<0.05)$ and $100(p<0.001) \mu \mathrm{M} \alpha$-tocopherol. In contrast, one-way ANOVA for total IsoPs was not significantly different among the different concentrations of $\alpha$-tocopherol. The increased NPs formed in synaptosomes by the addition of $\alpha$-tocopherol with AAPH were not proportionately distributed between F- and $\mathrm{D} / \mathrm{E}$-ring forms but rather displayed an $\alpha$-tocopherol concentration-dependent shift toward F-ring NPs. One-way ANOVA showed that increasing concentrations of $\alpha$-tocopherol significantly increased the F- to D/E-NP ratio $\left(F_{(3,8)}=87.2 ; p<\right.$ $0.0001)$ and that this increase was significantly different from AAPH alone at 10 and $100 \mu \mathrm{M} \alpha$-tocopherol $(p<0.001$ for both 


\begin{tabular}{|c|c|c|c|c|c|}
\hline & & \multirow{2}{*}{$\frac{w t}{\text { wale }}$} & \multirow{2}{*}{$\frac{\text { apoE-/- }}{\text { Male }}$} & \multirow{2}{*}{$\frac{\text { wt }}{\text { Female }}$} & \multirow{2}{*}{$\frac{\text { apoE-/- }}{\text { Female }}$} \\
\hline & & & & & \\
\hline Diet & Measure & & & & \\
\hline \multirow[t]{6}{*}{ Deficient } & Total IsoP & - & - & - & - \\
\hline & Total NP & - & $+81 \%$ & - & - \\
\hline & IsoP ratio & - & - & - & - \\
\hline & NP ratio & - & - & - & - \\
\hline & AA level & - & - & - & - \\
\hline & DHA level & $+13.0 \%$ & $+14.5 \%$ & $+14.2 \%$ & $+17.7 \%$ \\
\hline \multirow[t]{6}{*}{ Supplemented } & Total IsoP & $-37 \%$ & - & - & - \\
\hline & Total NP & - & - & - & - \\
\hline & IsoP ratio & - & - & - & - \\
\hline & NP ratio & $+289 \%$ & $+192 \%$ & - & - \\
\hline & AA level & - & - & - & - \\
\hline & DHA level & - & - & - & - \\
\hline
\end{tabular}
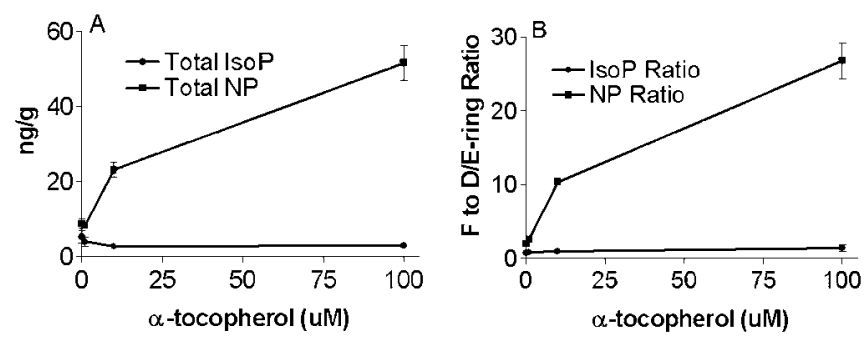

Figure 7. F- and D/E-ring NPs and IsoPs were determined in rat cerebral synaptosomes oxidized with AAPH in the presence of increasing concentrations of $\alpha$-tocopherol. $A$, Concentration-response relationship for total (F-ring plus D/E-ring) IsoPs and NPs. $B, \mathrm{~F}$ - to D/E-ring ratio for IsoPs and NPs.

concentrations) (Fig. 7B). In contrast, there was no change in the ratio of F2-IsoP to D2/E2-IsoP with increasing concentrations of $\alpha$-tocopherol.

\section{DISCUSSION}

Oxidative damage to cerebrum may be a central mechanism that contributes to age-related decline in cognitive function as well as a number of degenerative diseases of brain, including AD (Markesbery and Carney, 1999). Cerebral oxidative damage is not uniform throughout the population (Montine et al., 1999b,c), likely because of differences in inherited susceptibilities and environmental factors among individuals; however, little data are available on the specifics of these gene-environment interactions. We pursued the effects of gene-environment interactions from inherited susceptibility attributable to lack of apoE and the modulation of dietary $\alpha$-tocopherol on quantitative indices of cerebral oxidative damage in aged mice of both genders. The major findings from this investigation were as follows: (1) gender had a pervasive effect on cerebral oxidative damage and response to $\alpha$-tocopherol; (2) diet or genotype influenced oxidative damage to AA and DHA differently, strongly implying that quantification of oxidative damage to these two fatty acids reflects events in two different biochemical compartments in cerebrum, and (3) $\alpha$-tocopherol may exert its antioxidant activity in cerebrum through a combination of radical scavenging and enhanced reducing capacity.

Our results indicated that male gender should be considered a susceptibility factor for cerebral oxidative damage in this strain of mouse. Several studies have investigated behavioral and brain structural changes in aged $a p o E-/-$ mice. Although some groups have consistently observed differences between aged apoE $-/-$ mice and wt controls, several groups have been unable to replicate these findings (Masliah et al., 1995; Fagan et al., 1998; Montine et al., 1999a; Buttini et al., 2000). The basis for this discrepancy has not been clear. Our data suggest that gender composition of the study groups may be a key factor. Indeed, our results add to those of others showing significant differences between adult male and female apoE - /- mice (Raber et al., 1998). Contrary to male-specific effects observed in our study, women who have inherited an APOE4 allele are at greater risk for developing AD than men (Corder et al., 1993; Bretsky et al., 1999), and female transgenic mice that express a mutant form of the human amyloid precursor protein have greater senile plaque formation in brain at 15 months of age or older than males (Callahan et al., 2001). Although direct comparison among these studies is limited by the use of different models and different endpoints, they suggest a complex relationship among age, gender, age-related hormonal changes, and the different facets of AD pathogenesis. One study has shown that $\alpha$-tocopherol dietary supplementation ameliorates brain structural changes associated with aging in apoE $-/-$ mice, although these investigators did not specify any gender difference in the response to $\alpha$-tocopherol (Veinbergs et al., 2000). Our results also demonstrated coincident biochemical changes in brain that accompany $\alpha$-tocopherol supplementation. Thus, differences in diets, in addition to gender, may contribute to variation in results among different laboratories that have investigated aged $a p o E-/-$ mice.

Our studies showed that at least two risk factors are needed to increase cerebral AA oxidation (male gender and lack of apoE), whereas three risk factors (male gender, lack of apoE, and deficiency in $\alpha$-tocopherol) must combine to increase oxidative damage to DHA. As mentioned, AA is evenly distributed throughout gray matter and white matter, whereas DHA is concentrated in neurons (Salem et al., 1986; Moore, 1993). These data imply that cerebral AA exists in biochemical environments that are more prone to oxidative damage than are the environments that contain DHA. Neuron plasma membranes contain a much higher level of DHA than other cell types, presumably serving an important role in the membrane characteristics of neurons. There- 
fore, it is perhaps not surprising that additional mechanisms exist to protect DHA from oxidation in vivo. Our in vivo results showing increased total NP in male apoE -/- mice with deficiency in $\alpha$-tocopherol suggest that one mechanism to protect neuronal membranes is radical scavenging by $\alpha$-tocopherol.

The extent of AA and DHA oxidation responded differently to dietary supplementation with $\alpha$-tocopherol. The inability of increased brain $\alpha$-tocopherol to decrease basal total NPs suggests that the lower levels of brain $\alpha$-tocopherol achieved on the normal diet fully protected DHA. In contrast, $\alpha$-tocopherol supplementation did reduce AA oxidation in male wt mice, suggesting that normal diet did not provide full antioxidant protection to AA and providing additional evidence that $\alpha$-tocopherol preferentially protects cerebral DHA over AA in vivo. However, the results with cerebral AA oxidation on the supplemented diet are more complex because there was no reduction in total IsoPs in male apoE $-/-$ mice. One interpretation of these data are that male apoE $-/-$ mice may have reached a maximum plateau of IsoP levels that does not show response to increased brain $\alpha$-tocopherol, whereas the lower cerebral IsoP levels in male wt mice may still be in a range that is responsive to dietary supplementation with $\alpha$-tocopherol. Regardless of the mechanisms involved, an important public health consideration from these results is that normal dietary levels of $\alpha$-tocopherol provided maximum free radical scavenging protection for cerebral DHA but that long-term dietary supplementation achieved significantly higher $\alpha$-tocopherol levels in brain and augmented free radical protection for AA in wt male mice.

In addition to $\alpha$-tocopherol acting as an apparent radical scavenging agent in cerebrum, our results also suggested that, in vivo, $\alpha$-tocopherol may act as a reductant of the DHA endoperoxide but not the AA endoperoxide. Other antioxidants have both radical scavenging and reducing activity, the best example being glutathione. In vitro, $\alpha$-tocopherol has been shown to possess reducing activity for $\mathrm{Cu}(\mathrm{II})$ (Kontush et al., 1996), and we confirmed similar activity in the synaptosome experiments; however, we are unaware of any previous demonstration of this action of $\alpha$-tocopherol in vivo. The mechanisms by which $\alpha$-tocopherol had a selective reducing effect on DHA endoperoxide in vivo and in vitro are not clear. Possibilities include a preferential biochemical interaction between $\alpha$-tocopherol and DHA endoperoxide or possibly a higher concentration of $\alpha$-tocopherol in DHAcontaining compartments in vivo. Similar to others (Thomas and Stocker, 2000), we observed an in vitro pro-oxidant effect of $\alpha$-tocopherol, again selective for DHA over AA. Although the physiological significance of this in vitro pro-oxidant effect is not clear, these data do reinforce the conclusion of a preferential interaction of $\alpha$-tocopherol with DHA over AA.

In summary, we investigated the interaction of apoE and $\alpha$-tocopherol on cerebral oxidative damage in aged mice. By all measures, male mice were more vulnerable to cerebral oxidative damage than female mice. Multiple stressors were required to increase oxidative damage to cerebrum, although DHA appeared better protected from oxidative damage than was AA. The effects of $\alpha$-tocopherol in vivo were complex, demonstrating radical scavenging activity for both AA and DHA, depending on its concentration in brain, and reducing activity for the DHA endoperoxide, the latter activity being reproducible in vitro. Finally, we defined a significant interaction between lack of apoE and deficiency of $\alpha$-tocopherol in enhancing DHA but not AA oxidative damage. These results demonstrated that the interaction of gender, inher- ited susceptibilities, and diet contributed to age-related oxidative damage to cerebrum.

\section{REFERENCES}

Beckmam KB, Ames BN (1998) The free radical theory of aging matures. Physiol Rev 78:547-581.

Bretsky PM, Buckwalter JG, Seeman TE, Miller CA, Poirier J, Schellenberg GD, Finch CE, Henderson VW (1999) Evidence for an interaction between apolipoprotein E genotype, gender, and Alzheimer disease. Alzheimer Dis Assoc Disord 13:216-221.

Buttini M, Akeefe H, Lin C, Mahley RW, Pitas RE, Wyss-Coray T, Mucke L (2000) Dominant negative effects of apolipoprotein E4 revealed in transgenic models of neurodegenerative disease. Neuroscience 97:207-210.

Callahan MJ, Lipinski WJ, Bian F, Durham RA, Pack A, Walker LC (2001) Augmented senile plaque load in aged female $\beta$-amyloid precursor protein-transgenic mice. Am J Pathol 158:1173-1177.

Corder EH, Saunders AM, Strittmatter WJ, Schmechel DE, Gaskell PC, Small GW, Roses AD, Haines JL, Pericak VMA (1993) Gene dose of apolipoprotein E type 4 allele and the risk of Alzheimer's disease in late onset families. Science 261:921-923.

Elin RJ (1996) Laboratory reference intervals and values. In: Cecil textbook of Medicine, Ed 20 (Bennett JC, Plum F, eds), p 2228. Philadelphia: Saunders.

Fagan A, Murphy BA, Patel SN, Kilbridge JF, Mobley WC, Bu G, Holtzman DM (1998) Evidence for normal aging of the septohippocampal cholinergic system in apoE $(-/-)$ mice but impaired clearance of axonal degeneration products following injury. Exp Neurol 151:314-325.

Finkel T, Holbrook NJ (2000) Oxidants, oxidative stress, and the biology of ageing. Nature 408:239-247.

Gross MD, Prouty CB, Jacobs DR (1995) Stability of carotenoids and alpha-tocopherol during blood collection and processing procedures. Clin Chem 41:943-944.

Halliwell B (1992) Reactive oxygen species and the central nervous system. J Neurochem 59:1609-1623.

Jialal I, Traber M, Devaraj S (2001) Is there a vitamin E paradox? Curr Opin Lipidol 12:49-53.

Jiang CH, Tsien JZ, Schultz PG, Hu Y (2001) The effects of aging on gene expression in the hypothalamus and cortex of mice. Proc Natl Acad Sci USA 98:1930-1934

Kontush A, Meyer S, Finckh B, Kohlschutter A, Beisiegel U (1996) alpha-Tocopherol as a reductant for $\mathrm{Cu}$ (II) in human lipoproteins. J Biol Chem 271:11106-11112.

Mahley RW, Huang Y (1999) Apolipoprotein E: from athersclerosis to Alzheimer's disease and beyond. Curr Opin Lipidol 10:207-217.

Marcus R, Coulston AM (1996) Fat soluble vitamins. In: The pharmacological basis of therapeutics, Ed 9 (Hardman JG, Limbird LE, eds), pp 1573-1590. New York: McGraw-Hill.

Markesbery WR, Carney JM (1999) Oxidative alterations in Alzheimer's disease. Brain Pathol 9:133-146.

Masliah E, Mallory M, Ge N, Alford M, Veinbergs I, Roses AD (1995) Neurodegeneration in the central nervous system of apoE-deficient mice. Exp Neurol 136:107-122.

Montine K, Reich E, Olson SJ, Markesbery WR, Montine T (1998) Distribution of reducible 4-hydroxynonenal adduct immunoreactivity in Alzheimer's disease is associated with APOE genotype. J Neuropathol Exp Neurol 57:415-425.

Montine T, Montine K, Olson SJ, Graham DG, Roberts LJ, Morrow JD, Linton M, Fazio S, Swift LL (1999a) Increased cerebral cortical lipid peroxidation and abnormal phospholipids in aged homozygous apoEdeficient C57BL/6J mice. Exp Neurol 158:234-241.

Montine TJ, Beal MF, Cudkowicz ME, Brown RH, O'Donnell H, Margolin RA, McFarland L, Bachrach AF, Zackert WE, Roberts LJ, Morrow JD (1999b) Increased cerebrospinal fluid $F_{2}$-isoprostane concentration in probable Alzheimer's disease. Neurology 52:562-565.

Montine TJ, Markesbery WR, Zackert W, Sanchez SC, Roberts LJ, Morrow JD (1999c) The magnitude of brain lipid peroxidation correlates with the extent of degeneration but not with density of neuritic plaques or neurofibrillary tangles, or with $A P O E$ genotype in Alzheimer's disease patients. Am J Pathol 155:863-868.

Moore SA (1993) Cerebral endothelium and astrocytes cooperate in supplying docosahexaenoic acid to neurons. Adv Exp Med Biol 331:229-233.

Pratico D, Rokach J, Tangirala RK (1999) Brains of aged apolipoprotein E-deficient mice have increased levels of $\mathrm{F}_{2}$-isoprostanes, in vivo markers of lipid peroxidation. J Neurochem 73:736-741.

Pratico D, Clack CM, Lee VMY, Trojanowski JQ, Rokach J, FitzGerald G (2000) Increased 8,12-iso-iPF2a-IV in Alzheimer's disease: correlation of a noninvasive index of lipid peroxidation with disease severity. Ann Neurol 48:809-812.

Raber J, Wong D, Buttini M, Orth M, Bellosta S, Pitas RE, Mahley RW, Mucke L (1998) Isoform-specific effects of human apolipoprotein E on 
brain function revealed in apoE knockout mice: increased susceptibility of females. Proc Natl Acad Sci USA 95:10914-10919.

Reich E, Markesbery W, Roberts II L, Swift L, Morrow J, Montine T (2001) Brain regional quantification of F-ring and D/E-ring isoprostanes and neuroprostanes in Alzheimer's disease. Am J Pathol 158:293-297.

Reich EE, Zackert WE, Brame CJ, Chen Y, Roberts II LJ, Hachey DL, Montine TJ, Morrow JD (2000) Formation of novel D-ring and E-ring isoprostane-like compounds $\left(\mathrm{D}_{4} / \mathrm{E}_{4}\right.$-neuroprostanes) in vivo from docosahexaenoic acid. Biochemistry 39:2376-2383.

Roberts II LJ (2000) Measurement of $\mathrm{F}_{2}$-isoprostanes as an index of oxidative stress in vivo. Free Radic Biol Med 28:505-513.

Roberts LJ, Montine TJ, Markesbery WR, Tapper AR, Hardy P, Chemtob S, Detbarn WD, Morrow JD (1998) Formation of isoprostane-like compounds (neuroprostanes) in vivo from docosahexaenoic acid. J Biol Chem 273:13605-13612.

Salem N, Kim HY, Yergey JA (1986) Docosahexaenoic acid:membrane function and metabolism. In: Health effects of polyunsaturated acids in seafoods (Simopoulos AP, Kifer RR, Martin RE, eds), pp 263-317. New York: Academic.

Sano M, Ernesto C, Thomas RG, Klauber MR, Schafer K, Grundman M, Woodbury P, Growdon J, Cotman CW, Pfeiffer E, Schneider LS, Thal LJ (1997) A controlled trial of selegiline, alpha-tocopherol, or both as a treatment for Alzheimer's disease. N Engl J Med 336:1216-1222.

Sayre LM, Zelasko DA, Harris PLR, Perry G, Salomon RG, Smith MA (1997) 4-Hydroxynonenal-derived advanced lipid peroxidation end products are increased in Alzheimer disease. J Neurochem 2092-2097. Thomas SR, Stocker R (2000) Molecular action of vitamin E in lipoprotein oxidation: implications for atherosclerosis. Free Radic Biol Med 28:1795-1805.

Veinbergs I, Mallory M, Sagara Y, Masliah E (2000) Vitamin E supplementation prevents spatial learning deficits and dendritic alterations in aged apolipoprotein E-deficient mice. Eur J Neurosci 12:4541-4546. 